\title{
A case of frontotemporal dementia
}

\author{
Heng Siang Ting, B M Yashodhara, Bashir Ahmad Dar, Uduman Ali \\ Mohamed Yousuf, Adinegara Lutfi Abas
}

\begin{abstract}
Introduction: Frontotemporal dementia is a common cause of dementia. It is easily misdiagnosed as a psychiatric illness due to its presentation with behavioral problems, mutism, language problems and in some cases with aggression and anti-social behavior. Case Report: We report a case of a 72-year-old man who presented with behavioral abnormalities, lack of personal hygiene, personality changes of gradual onset for 2-3 years, suggested by inability to take care of self, mutism, social disinhibition in the form of micturition in the presence of family members. Computed tomography (CT) scan of the brain showed atrophy of frontal and temporal lobes. The family members were counseled for the outcome and prognosis of the case. Conclusion: The diagnosis of frontotemporal dementia is made based on presentation, diagnostic criteria and brain imaging. Definite treatment is not
\end{abstract}

Heng Siang Ting ${ }^{1}$, B M Yashodhara², Bashir Ahmad Dar², Uduman Ali Mohamed Yousuf ${ }^{3}$, Adinegara Lutfi Abas ${ }^{4}$ Affiliations: ${ }^{1}$ Final year Medical Student, Melaka Manipal Medical College, Melaka, Malaysia; ${ }^{2}$ Associate Professor, Department of Medicine, Melaka Manipal Medical College, Melaka, Malaysia; ${ }^{3} \mathrm{HOD}$, Department of Medicine, Melaka Manipal Medical College, Melaka, Malaysia; ${ }^{4}$ Deputy Dean, HOD, Department of Community Medicine, Melaka Manipal Medical College, Melaka, Malaysia.

Corresponding Author: Dr. Yashodhara BM, Associate Professor, Department of Medicine, Melaka Manipal Medical College 75150, Melaka, Malaysia; Ph: 0060176948029; Fax: 0062817977; Email: bmyashodhara@gmail.com available, but treating according to presenting complaints of the patient is helpful; e.g. if the patient has depression, anti-depressants along with family counselling about the progression of the disease and awareness about requirement for the family support are important.

Keywords: Dementia, Frontotemporal, Abnormal behavior, Poor personal hygiene

$$
* * * * * * * * *
$$

Ting HS, Yashodhara BM, Dar BA, Yousuf UAM, Abas AL. A case of frontotemporal dementia. International Journal of Case Reports and Images 2013;4(3):175-179.

$$
* * * * * * * * *
$$

doi:10.5348/ijcri-2013-03-288-CR-9

\section{INTRODUCTION}

Dementia is a common disease in middle age and elderly. It may be due to Alzheimer's disease, vascular dementia, frontotemporal dementia (FTD) or Lewy body dementia. It may also be due to secondary causes like HIV infection, Huntington's disease, head injury, Parkinson's disease, metabolic and endocrine diseases, poisoning, infections like neurosyphilis, vitamin deficiencies, normal pressure hydrocephalus and pseudo-dementia due to depression.

Alzheimer disease patients typically present with problems in cognitive functions; memory, executive functions, language and constructional praxis. On brain scanning there is atrophy of the brain from occipital lobe to parietal lobe and later in the disease of the frontotemporal areas. Patients tend to get lost and find it difficult to get back to their place due to problems in visual-spatial skills. They also lose things easily. Patients of frontotemporal dementia typically have problems in behavior, personality and language when 
assessed by neuropsychiatric battery of tests but have intact visual-spatial skills. The presenting features are in the form of behavioral abnormalities like anti-social conduct, poor personal grooming, thefts and vehicle accidents. Generally the diagnosis is not made early by non-specialists, even though it is one of the common causes of dementia.

\section{CASE REPORT}

A 72-year-old man presented with history of poor oral intake for two days, chills and rigors, without the presence of fever on daily temperature recording. As he was not able to give accurate history, his daughter was interviewed and it was found that the patient has had personality change for 2-3 years now. It was insidious in onset and progressively worsening. Daughter noticed that patient had problems with memory, particularly short term memory loss, with patient not being able to remember the task he was doing at a time. Patient was also found to have multiple, minor, motor vehicle accidents, but he was not able to recall what happened. Patient also frequently misplaced things. The patient could still recognize family members, and was able to drive out alone without getting lost. For the past one year, patient had a gradual onset of disinhibition. He did not have urinary incontinence, but he would urinate anywhere and anytime at home even in the presence of other family members. He also became more reserved, communicated poorly with family members and at times was found to be non-responsive to questions. Patient's daughter also noticed that patient has peculiar behaviors on and off; such as sudden thought block and smiling to himself. He did not have visual hallucinations. The patient's daughter observed that he had vesicular rash on his left thigh which was painful and not itchy. There was no history of previous head trauma, no fever, no movement disorders and no history of frank delusion or hallucination. There was no previous history of psychiatric disorder in the patient or family members. On examination, the patient was alert and conscious with GCS 15/15. However, he was not paying attention to his surroundings. He was afebrile, pulse rate was 83 beats per min, and blood pressure was 128/62 mmHg. A tender, erythematous vesicular lesion was found on left thigh. All cranial nerves were found to be intact. Speech was normal, but at times patient would become mute. His mini mental state examination (MMSE) score was 21/30, as assessed recently on follow up by one of the attending neurologist. He was found to have positive sucking, palmo-mental reflexes. Rest of central nervous system examination and other examinations for respiratory, cardiovascular, gastrointestinal and musculoskeletal systems were essentially normal.

Patient's full blood count, renal functions, thyroid functions, liver functions and routine urine examinations were normal. He tested negative for HIV, Hepatitis B, Hepatitis C, venereal disease research laboratory test (VDRL), and treponema palladium hemagglutination test (TPHA). His serum electrolytes were normal. Based on the history and clinical presentation, a diagnosis of dementia with Herpes simplex of left thigh was considered. Computed tomography scan of the brain showed atrophy of frontal and temporal areas of the brain (Figures 1-4).

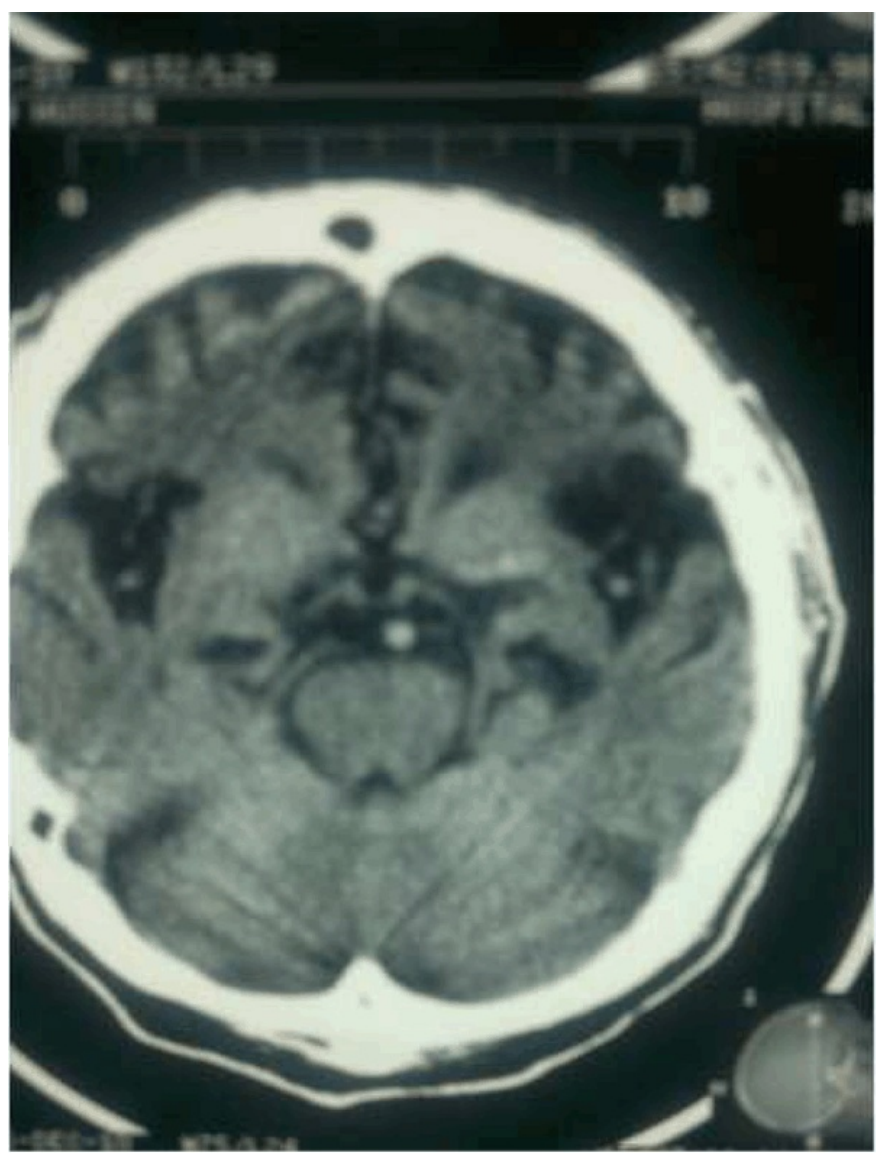

Figure 1: Bifrontotemporal atrophy and prominent sylvian fissures. Frontal horns of ventricles are just visible.

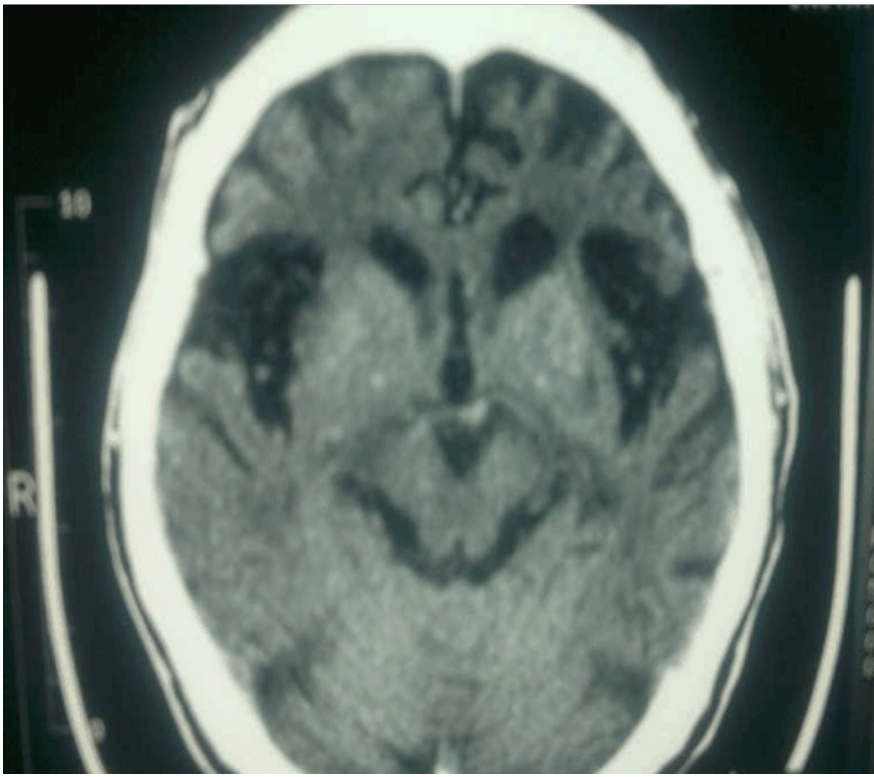

Figure 2: Bifrontotemporal atrophy and prominent sylvian fissures. Frontal horns of ventricles are clearly visible. 


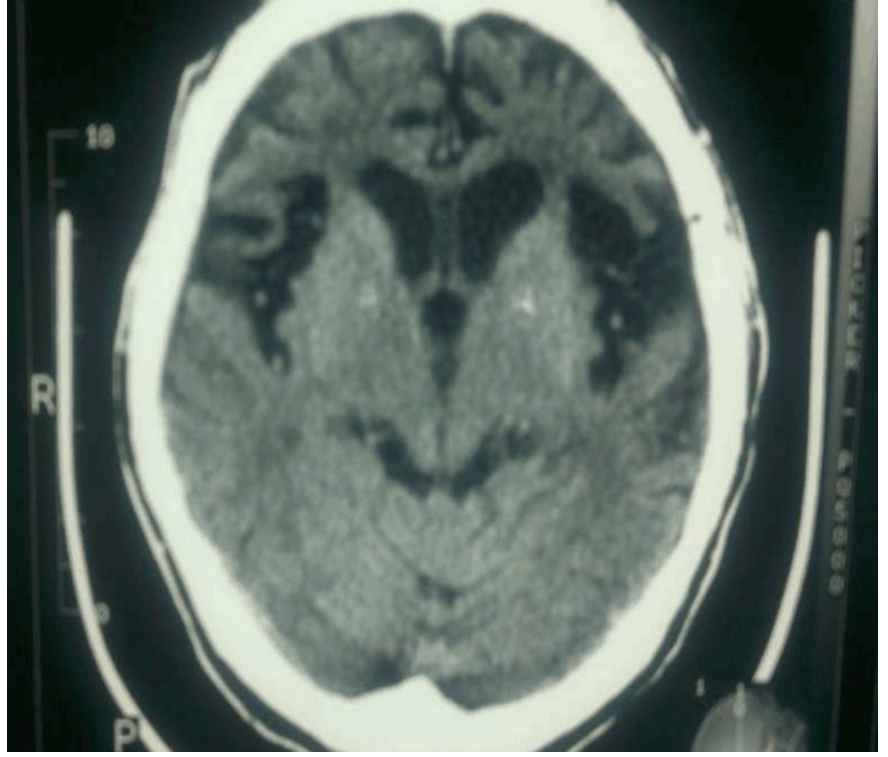

Figure 3: Bifrontotemporal atrophy and prominent sylvian fissures. Frontal horns of the ventricles are dilated.

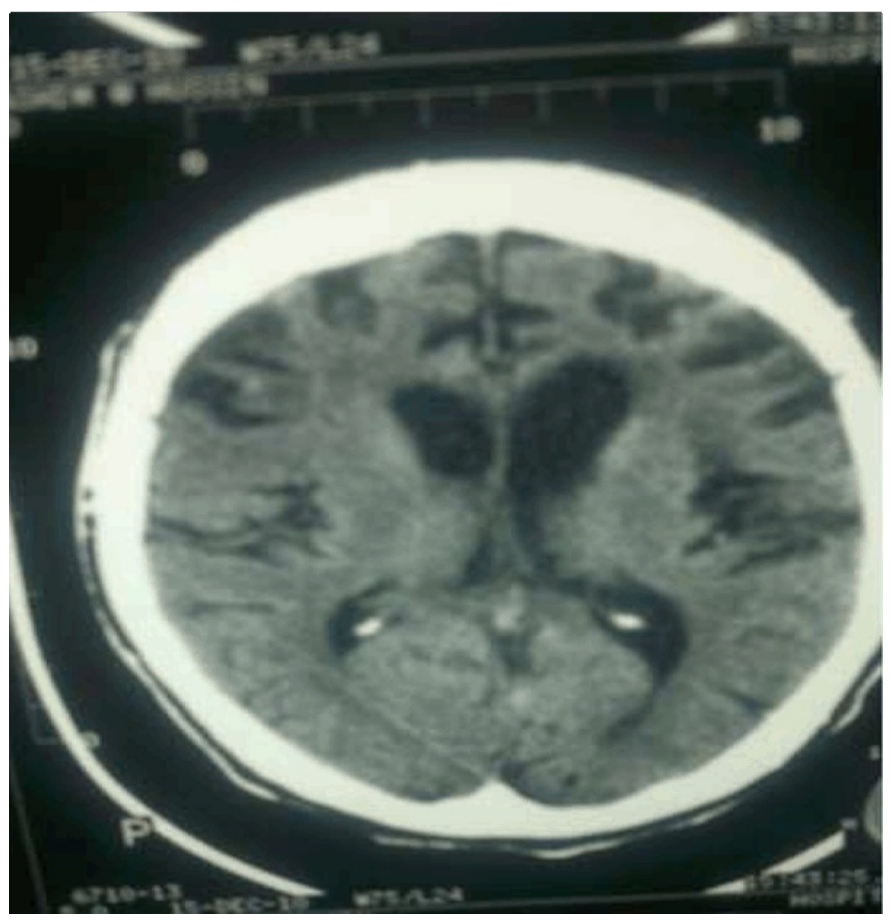

Figure 4: Prominent dilated ventricles. Left ventricle was dilated more than the right ventricle.

A find diagnosis of frontotemporal dementia with rash due to herpes simplex infection on left thigh was made. He received acyclovir $200 \mathrm{mg} 5$ times a day for 5 days at discharge. The daughter was counseled about the disease and its progression and follow up. The family members were very supportive to the patient. They were advised to not to let patient drive on his own.

\section{DISCUSSION}

Frontotemporal dementia is one of the causes of early-onset dementia (EOD) and has a $2.6 \%$ prevalence. Vascular dementia (42.5\%), and Alzheimert disease (25.6\%) are the most common causes, as noted in a population based study from Japan [1]. Frontotemporal dementia is a focal form of dementia in the presenium, yet remains poorly recognized [2], It is frequently mistaken for Alzheimer's disease or psychiatric diseases [3]. The age of onset of FTD is somewhat younger than other degenerative dementias, with a mean age of onset of about 58 years $[4,5]$. It is now recognized as one of the three types of frontotemporal lobar degenerations (FTLD); frontotemporal dementia, semantic dementia and progressive nonfluent aphasia [PNFA] [5]. The prevalence of FTD is variable in different age ranges: $3.6 / 100000$ at age $50-59$ years, $9.4 / 100000$ at age $60-69$ years and $3.8 / 100000$ at age $70-79$ years [4] The reported age of onset ranges from 33 to 80 years [4], with a male predominance in FTD and semantic dementia [5]: Frontotemporal dementia is the second most common cause of dementia in patients less than 65 years of age [5]. Our patient developed frontotemporal dementia of 72 years of age.

Macroscopic examination of the brain of a patient with FTLD typically shows symmetrical focal atrophy of the frontal lobes, temporal lobes. Microscopic examination of the cerebral cortex in most forms of FTLD, shows microvacuolation and neuronal loss. On staining for deposits in neurons, abnormal tau protein aggregates (46\%) and ubiquitin-positive inclusions (29\%) were found [6]. Our patient had frontal and temporal lobe atrophy on CT scan. The exact etiology and pathophysiology of frontotemporal dementia is incompletely understood but recent studies suggest that genetics plays an important role in disease causation [7]. This is supported by the fact that about $50 \%$ of patients with frontotemporal dementia (FTD) report a positive family history [7].

Patients with FTD display a heterogeneous clinical picture, which may include behavioral, cognitive, and motor manifestations [8]. They can be divided into two variants: the behavioral variant and the language variant (also referred as primary progressive aphasia) [8]. The behavioral variant, which was a likely variant in our patient is characterized by progressive personality changes, lack of insight, loss of social awareness, emotional blunting and loss of empathy [8]. The language variant on the other hand can be further divided into a well-defined clinic-pathological entity, semantic dementia (SD), and progressive nonfluent aphasia (PNFA) [8]. Progressive nonfluent aphasia is characterized by a progressive deficit in language, starting from anomia and agramatism progressing to dysfluent spontaneous speech and eventually mutism [8]. Our patient had shown features of mutism, during his admission in the in-patient department and was also noted by the daughter of the patient. The vesicular rash on the thigh in our patient, was diagnosed to be due to Herpes simplex and was treated appropriately. 
Frontotemporal dementia is largely made by clinical assessment, as in our case. Neuroimaging studies are equally important to provide supportive evidence for diagnosis as well as to exclude other structural diseases [8]. Multiple diagnostic criteria to aid in diagnosis (Table 1) have been devised and published [9]. Treatment mode available for frontotemporal dementia is very limited as there are no currently FDA-approved diseases modifying treatments [10]. Hence, off-label medication usage is frequent in the hope to cope with its devastating functional disability. Antidepressant and antipsychotic medications, (US FDA-approved treatments for Alzheimer's disease) including cholinesterase inhibitors and memantine have been used [10]. Antidepressant and antipsychotic medications [11], have proven to give some benefits while cholinesterase inhibitors have limited efficacy [12]. The role of memantine in frontotemporal dementia is under further evaluation [10].

Table 1: Clinical and investigational diagnostic criteria for frontotemporal dementia

\begin{tabular}{|c|c|c|c|}
\hline Behavioural & $\begin{array}{l}\text { Affective and speech } \\
\text { symptoms }\end{array}$ & $\begin{array}{l}\text { Physical signs and } \\
\text { Investigational }\end{array}$ & Exclusions \\
\hline Insidious onset & Depression, anxiety & Pamlomental reflex & Abrupt onset \\
\hline Lack of personal hygiene & \multirow{6}{*}{$\begin{array}{l}\text { Emotional } \\
\text { unconcern/indifference } \\
\text { Echolalia, progressive reduction } \\
\text { in speech and mutism. }\end{array}$} & Sucking reflex & Head trauma related to onset \\
\hline Early signs of disinhibition & & Glabellar tap & \multirow{5}{*}{$\begin{array}{l}\text { Cerebellar ataxia, corticobulbar } \\
\text { and spinal deficits } \\
\text { Brain imaging (post-central } \\
\text { structural/functional deficits or } \\
\text { multifocal infarcts on CT or MRI) }\end{array}$} \\
\hline Stereotyped behavior (clapping, & & Normal EEG & \\
\hline dancing, singing etc) & & \multirow{3}{*}{$\begin{array}{l}\text { Brain imaging findings } \\
\text { (frontal and temporal } \\
\text { lobe atrophy) }\end{array}$} & \\
\hline Loss of insight & & & \\
\hline $\begin{array}{l}\text { Utilization behavior - unrestrained } \\
\text { exploration of objects in the } \\
\text { environment }\end{array}$ & & & \\
\hline
\end{tabular}

\section{CONCLUSION}

Frontotemporal dementia is easy to diagnose and should be suspected in middle age and elderly persons presenting with gradual onset of personality changes, aggressive behavior, apathy and mutism. It is easily diagnosed by standard criteria and brain scan findings. Family history may be positive in some cases.

$* * * * * * * * *$

\section{Author Contributions}

Heng Siang Ting - Substantial contributions to conception and design, Acquisition of data, Drafting the article, Revising it critically for important intellectual content, Final approval of the version to be published Yashodhara BM - Substantial contributions to conception and design, Acquisition of data, Drafting the article, Revising it critically for important intellectual content, Final approval of the version to be published Bashir Ahmad Dar - Substantial contributions to conception and design, Analysis and interpretation of data, Final approval of the version to be published Uduman Ali Mohamed Yousuf - Substantial contributions to conception and design, Analysis and interpretation of data, Final approval of the version to be published

Adinegara Lutfi Abas - Substantial contributions to conception and design, Analysis and interpretation of data, Final approval of the version to be published

\section{Guarantor}

The corresponding author is the guarantor of submission.

\section{Conflict of Interest}

Authors declare no conflict of interest.

\section{Copyright}

(C) Heng Siang Ting et al. 2013; This article is distributed under the terms of Creative Commons Attribution 3.0 License which permits unrestricted use, distribution and reproduction in any means provided the original authors and original publisher are properly credited. (Please see www.ijcasereportsandimages.com /copyright-policy.php for more information.)

\section{REFERENCES}

1. Chiaki Ikejima, Fumihiko Yasuno, Katsuyoshi Mizukami, Megumi Sasaki, Satoshi Tanimukai, Takashi Asada. Prevalence and Causes of EarlyOnset Dementia in Japan: A Population-Based Study. Stroke 2009;40(8):2709-14.

2. Snowden JS, Neary D, Mann DM. Frontotemporal dementia. The British Journal of Psychiatry 2002;180:140-3.

3. McKhann GM, Albert MS, Grossman M, Miller B, Dickson D, Trojanowski JQ. Clinical and Pathological Diagnosis of Frontotemporal Dementia, Report of the Work Group on Frontotemporal 
Dementia and Pick's Disease. Arch Neurol 2001;58(11):1803-9.

4. Rosso SM, Donker Kaat L, Baks T, et al. Frontotemporal dementia in The Netherlands: patient characteristics and prevalence estimates from a population-based study. Brain 2003 Sep;126(Pt 9):2016-22.

5. Johnson JK, Diehl J, Mendez MF, et al. Frontotemporal Lobar Degeneration: Demographic Characteristics of 353 Patients. Arch Neurol 2005;62(6):925-30.

6. Forman MS, Farmer J, Johnson JK, et al. Frontotemporal dementia: Clinicopathological correlations. Ann Neurol 2006;59(6):952-62.

7. Christian Wider, Zbigniew K Wszolek. Etiology and Pathophysiology of Frontotemporal Dementia, Parkinson Disease and Alzheimer Disease: Lessons from Genetic Studies. Neurodegener Dis 2008;5(34):122-5.

8. Leyton CE, Hodges JR. Frontotemporal dementias: Recent advances and current controversies. Ann Indian Acad Neurol 2010;13(Suppl 2):S74-80.
9. Neary D, Snowden JS, Gustafson L, et al. Frontotemporal lobar degeneration: a consensus on clinical diagnostic criteria. Neurology 1998 Dec;51(6):1546-54.

10. Geoffrey A Kerchner, Maria Carmela Tartaglia, Adam L Boxer. Abhorring the vacuum: use of Alzheimer's disease medications in frontotemporal dementia. Expert Rev Neurother 2011 May;11(5):709-17.

11. Florence Lebert, Willy Stekke, Christine Hasenbroekx, Florence Pasquier. Frontotemporal Dementia: A Randomised, Controlled Trial with Trazodone. Dement Geriatr Cogn Disord 2004;17(4):355-9.

12. Mendez MF, Shapira JS, McMurtray A, Licht E. Preliminary Findings: Behavioural Worsening on Donepezil in Patients With Frontotemporal Dementia. American Journal of Geriatric Psychiatry 2007 January;15(1):84-7.
Access full text article on other devices

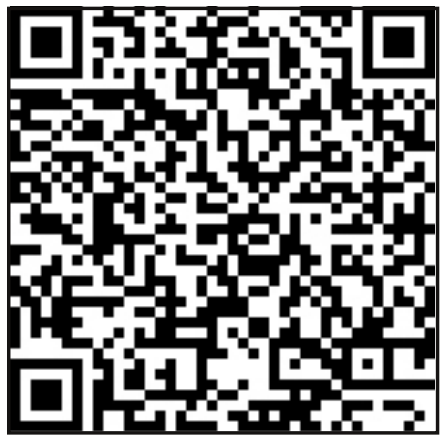

Access PDF of article on other devices

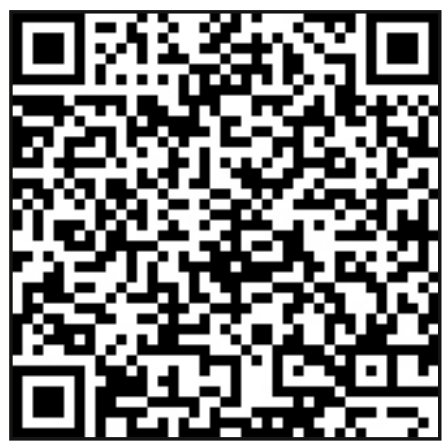

